\title{
Are meal deals making us fat? An investigation into whether cost-led meal deals encourage increased energy, saturated fat, sugar and salt consumption
}

\author{
C.H. Ellis and D. Bhakta \\ Faculty of Life Sciences \& Computing, London Metropolitan University, Holloway Road, London, N7 8DB.
}

Price promotions are consistently linked to consumer behaviour with a reported $50 \%$ spend in UK supermarkets driven by promotions ${ }^{(1)}$. We investigated whether the purchasing of supermarket lunch time meal deals, typically consisting of a main meal, snack and drink for a set price may lead to an increase in consumption of energy, saturated fat, sugar and salt especially if 'unhealthy' options are selected ${ }^{(2)}$.

The study was conducted during the lunch hours of 11:00 to 14:00 covering four demographically different areas of London and supermarkets: Islington (Sainsbury's), City of London (Tesco \& Sainsbury's), Peckham (Morrisons) and Deptford (Tesco). A questionnaire was developed and piloted to capture information on items purchased, habitual lunch and socio-economic factors. The questionnaire was administered by face-to-face interview using a portable tablet computer utilising the online survey tool SurveyMonkey (3). There were no statistical differences in age, gender, ethnicity or education between the participants who purchased the meal deal $(n$ 44) and those who did not ( $n$ 18).

Participants who selected the meal deal consumed significantly more energy and salt than the participants which did not select the meal deal (see Table below). There were no significant differences in saturated fat intake or sugar consumption. However, energy, saturated fat, sugar and salt intake were all significantly higher $(P<0.001$; data not shown) when comparing habitual lunch with the meal deal.

\begin{tabular}{|c|c|c|c|c|c|}
\hline & Purch & & Did no & & \\
\hline & $n 44$ & & $n 18$ & & \\
\hline & Mean & $(S D)$ & Mean & $(S D)$ & $P$-value* \\
\hline Energy (kcal) & 702 & $(170)$ & 598 & $(201)$ & $0 \cdot 04$ \\
\hline Saturated fat (g) & 5 & $(3 \cdot 1)$ & $4 \cdot 6$ & $(3 \cdot 1)$ & $N S$ \\
\hline Sugar (g) & 38 & $(24 \cdot 6)$ & $31 \cdot 6$ & $(24 \cdot 6)$ & $N S$ \\
\hline Salt (g) & $2 \cdot 1$ & $(0.5)$ & 1.7 & $(0.4)$ & 0.003 \\
\hline
\end{tabular}

* significant at $P<0.05$

Interestingly, whilst cost saving was cited as a key driver in the meal deal selection, this was not related to income, as there were no significant differences between high and average earners (defined as earnings above and below $£ 40 \mathrm{~K}$, respectively) in those selecting the meal deal.

These results support the literature on out-of-home dining and the effect of increased energy consumption ${ }^{(4)}$. Pressure should be put on retailers to reform offers by improving healthy options, making them more accessible and improve the marketing of healthy items available in the offer.

1. Dobson P.W. (2011) www.esrc.ac.uk/my-esrc/grants/RES-000-22-3524-A/read Accessed April 2014

2. Chandon P., Wansink B. (2007) J Consum Res. 34, 301-315.

3. SurveyMonkey ${ }^{\mathbb{B}}$ https://www.surveymonkey.com/accessed April 2014.

4. Jaworowska A., Blackham T., Davies I.G. et al. (2013) Nutr Rev. 71, 310-318. 